\title{
O ENSINO DE FILOSOFIA E A PEDAGOGIA DO CONCEITO; UMA ABORDAGEM NECESSÁRIA NO ÂMBITO DO ENSINO MÉDIO
}

\author{
José Renato de Araújo Sousa ${ }^{1}$ \\ Gleison Lima da Silva ${ }^{2}$
}

\section{Resumo:}

Ao pensar as linhas e o percurso histórico do ensino de filosofia no Brasil, especificamente no âmbito do ensino médio iremos nos deparar com inúmeros paradoxos e tensões curriculares que não favorecem a relação do ensino de filosofia com a pedagogia do conceito, impedindo assim que esta atividade meramente pedagógica venha a se tornar um exercício verdadeiramente filosófico. Nesse sentido, à luz dos filósofos franceses Gilles Deleuze e Félix Guattari, torna-se relevante explicitar a pedagogia do conceito e suas possíveis contribuições para o ensino de filosofia no contexto do ensino médio. A partir do diálogo com estes e outros teóricos, teremos como objetivo pensar a pedagogia do conceito como possibilidade de construção de saberes filosóficos e superação do ensino de filosofia tradicional. A metodologia utilizada para a construção de saberes neste estudo foi à pesquisa bibliográfica a partir da leitura atenta de teóricos como Deleuze (1992), Severino (2010), Gallo (2012), documentos oficiais como os Parâmetros Curriculares Nacionais (1999) dentre outros. O artigo está organizado em uma breve introdução apresentando a temática, os objetivos, o percurso metodológico, dois capítulos subsequentes enfatizando algumas problematizações válidas e necessárias acerca do uso do ensino de filosofia no ensino médio sob a perspectiva Deleuzoguattariana, em seguida, as considerações finais sintetizando as principais ideias discutidas ao longo do texto.

Palavras-chave: Ensino. Filosofia. Conceito. Criação.

\section{THE TEACHING OF PHILOSOPHY AND THE PEDAGOGY OF THE CONCEPT; A NECESSARY APPROACH IN THE FRAMEWORK OF HIGH SCHOOL}

\begin{abstract}
When thinking about the lines and historical path of teaching philosophy in Brazil, specifically in the context of high school, we will come across numerous paradoxes and curricular tensions that do not favor the relationship between the teaching of philosophy and the pedagogy of the concept, thus preventing this activity merely pedagogical will become a truly philosophical exercise. In this sense, in the light of the French philosophers Gilles Deleuze and Félix Guattari, it becomes relevant to explain the pedagogy of the concept and its possible contributions to the teaching of philosophy in the context of high school. Based on the dialogue with these and other theorists, we aim to analyze the pedagogy of the concept as a possibility for building philosophical knowledge and overcoming the teaching of traditional philosophy. The methodology used for the construction of knowledge in this study was bibliographic research based on a careful reading of theorists such as Deleuze (1992), Severino (2010), Gallo (2012), official documents such as the National Curriculum Parameters (1999) among others. The article is organized in a brief introduction presenting the theme, the objectives, the methodological path, two subsequent chapters emphasizing some valid and necessary reflections on the use of philosophy teaching in high school under the Deleuzoguattariana perspective, then a conclusion summarizing the main ideas discussed throughout the text.
\end{abstract}

Keywords: Teaching. Philosophy. Concept. Creation.

\footnotetext{
1 Professor Doutor do Programa de Pós-Graduação em Filosofia da UFPI. renatocacto@ hotmail.com. http://orcid.org/0000-0002-6988-7426

2 Mestrando em Filosofia pela Universidade Federal do Piauí - UFPI. gleisonlimalima @ gmail.com. http://orcid.org/0000-0002-3113-0962
} 


\section{Introdução}

O ensino de filosofia na escola secundária brasileira já existe desde o período do Brasil colônia e desde então já se nota a enorme dificuldade da consolidação da filosofia enquanto componente curricular. Devido às diferentes orientações que foram ao longo do tempo sendo conferidas a esse nível de ensino, os diferentes sentidos e as mais diversas finalidades da filosofia enquanto disciplina, também acabaram sofrendo muitas oscilações. Por essa e outras razões, nos últimos tempos o ensino de filosofia no ensino médio tem se tornado alvo de muitas discussões.

$\mathrm{O}$ retorno da mesma às escolas se deu com a aprovação Lei n. 11.684/08, que modifica o Art. 36 da Lei 9.394/96 e legislou que os estados a incluíssem como disciplina obrigatória nos currículos de ensino médio brasileiro. A volta da Filosofia trouxe consigo a intensa necessidade de um material didático e metodologias diferenciadas que se adéquam ao ensino da mesma e também uma necessária reflexão acerca da enorme divergência percebida entre a real proposta da filosofia enquanto componente curricular do ensino médio e o trabalho que vem sendo desenvolvido pelos professores em sala de aula.

O que se percebe é que existem inúmeras tensões curriculares e metodológicas no ensino de Filosofia do Ensino Médio e estas por sua vez são apontadas como entraves para que os alunos venham a compreender o verdadeiro significado da Filosofia na escola e também fora dela. Em meio a esse contexto, podemos afirmar ainda que os professores convivem diariamente com diversos problemas, dentre eles as metodologias marcadas por um ensino “explicador” baseado na mera transmissão de conteúdos, ausência de problematização e produção de conceitos, uso exclusivo do livro didático e sem pensar criticamente sobre os diferentes tipos de conteúdos.que marcam a vida dos educandos e a consequente transmissão das ideologias presentes nestes recursos didáticos.

Partindo destas concepções introdutórias, o objetivo geral deste trabalho é pensar uma proposta de ensino de filosofia no ensino médio a partir da pedagogia do conceito conforme a teoria filosófica de Gilles Deleuze e Félix Guattari. Em meio a esse contexto, buscaremos ainda compreender a partir do diálogo com estes e outros teóricos, a pedagogia do conceito como possibilidade de construção de saberes filosóficos e superação do ensino de filosofia tradicional tendo em vista que Deleuze criticava a visão da filosofia clássica por contrapor a sua perspectiva filosófica.

\begin{tabular}{|l|l|l|l|l|}
\hline Q Povista Dialectus & Ano 10 & n. 23 & Maio - Agosto 2021 & p. $120-137$ \\
\hline
\end{tabular}


A metodologia utilizada para a construção de saberes neste estudo foi à pesquisa bibliográfica a partir da leitura atenta de teóricos como Deleuze (1992), Severino (2010), Gallo (2012), documentos oficiais como os Parâmetros Curriculares Nacionais (1999) dentre outros.

\section{Considerações necessárias para se pensar o Ensino de Filosofia nos dias atuais}

Para pensar o ensino de filosofia nos dias atuais é indispensável que pensemos em inúmeras questões que direta ou indiretamente estão relacionadas a esse mesmo contexto, dentre elas, a função do professor de filosofia do ensino médio. Na obra intitulada "Filosofia e seu Ensino" publicado pela Editora PUC-SP no ano de 1995, o autor Franklin Leopoldo e Silva fala sobre a função social do filósofo, fazendo uma abordagem sistematizada acerca da função do filósofo na sociedade, dando ênfase ao fato de que "sua função não se esgota na perspectiva da explicação ou das condições histórico sociais da produção teórica em filosofia." E diante disso, o texto nos convida a pensar a função social do filósofo diante do risco da relação mecanicista que se pode estabelecer pela negligencia das mediações entre história e subjetividade.

Nesse contexto, o autor nos coloca a filosofia, a escola, o professor, o contexto do aluno e as imposições estruturais do sistema educacional, como instrumentos que precisam ser melhor pensados. Reforçando ainda mais essa questão, Alejandro Cerletti nos traz na sua obra O ensino de filosofia como problema filosófico, que os questionamentos sobre o que é filosofia e o que significa ensiná-la, mantêm estreita relação, enlaçando aspectos cruciais da atividade filosófica. Segundo ele:

Poderíamos perguntar-nos antes de mais nada, se é realmente possível ensinar filosofia sem uma intervenção filosófica sobre os conteúdos e as formas de transmissão dos "saberes fillosóficos"; ou sem responder, univocamente, que é filosofia? Ou também sem se colocar que tipo de análise social, institucional ou filosófico político do contexto é requerido;ou as condições sob as quais se levará adiante esse ensino.É evidente que não é o mesmo "dar aulas" de filosofia em uma escola de uma zona socialmente muito castigada da periferia suburbana do que em um colégio urbano de classe alta ou em uma escola rural do interior do país, ou na universidade para alunos que não cursam filosofia ou em uma graduação em filosofia etc. Não porque consideremos que há circunstâncias nas quais é possível ensinar melhor do que em outras, mas porque em função desses contextos, não será o mesmo em cada caso o que se pode - ou se deve - fazer em nome da filosofia. (CERLETTI, 2008.p.08).

O pensamento do autor evidencia que há uma necessidade de se pensar o ensino de filosofia a partir de cada realidade, de cada contexto, buscando romper com os princípios

\begin{tabular}{|l|l|l|l|l|}
\hline Rovista Dialectus & Ano 10 & n. 23 & Maio - Agosto 2021 & p. 120 - 137 \\
\hline
\end{tabular}


didáticos tradicionais que reproduzem historicamente os conhecimentos filosóficos sem antes pensarem as suas práticas, e readequarem-nas filosoficamente aos diversos contextos onde se estão ensinando ou se pretende ensinar.

Pensando filosoficamente o seu ensino a partir da própria filosofia seremos levados a compreender que os conhecimentos filosóficos estão para além do método, para além das diretrizes e parâmetros curriculares, para além das relações de vínculo didático pedagógicos. Isso porque a filosofia se encontra em um panorama de ensino paradoxal quando pensamos a sua real importância e a forma como esta tem sido ensinada.

No capítulo III da obra Diferença e Repetição, ao falar da imagem do pensamento Deleuze evidencia que "não se sabe como alguém aprende." Pensando a partir disso, compreende-se também que não há método para ensinar se levarmos em consideração as diferentes perspectivas de ensino de filosofia adotada pelos professores, uma vez que as turmas não são homogêneas, as concepções filosóficas docentes muito menos, e frente a esse contexto discursivo é importante salientar que o ensino de filosofia está completamente relacionado com uma adoção do que se pensa sobre "o que é a filosofia?".

Por esta e outras razões, pensamos que o ensino desta disciplina precisa ser repensado, ser atualizado cotidianamente levando em consideração a realidade da classe de docentes e discentes, (apontados aqui como protagonistas desse processo), os seus múltiplos elementos e o contexto educacional em que se dar o ato filosófico de aprender e ensinar.

Pensar o exercício da filosofia no ensino médio de hoje requer esforço, compreensão e abertura à diversidade diante da contradição presente entre àquilo que é pregado pela legislação e a sua aplicação como componente curricular uma vez que a legislação determina que a filosofia deve ser metodicamente ensinada, especificando ainda quais objetos de conhecimento devam ser ministrados pelo professor e quais habilidades e competências devem ser esperadas a partir do ensinamento dos respectivos conteúdos.

O fato é que a filosofia proposta hoje para o ensino médio é uma filosofia que está voltada para a unificação conceitual, na grande maioria das vezes, girando em torno apenas da formação cidadã do individuo.Mas quem nos assegura que esses conhecimentos propostos pela legislação são de fato ideais para se chegar a esse fim? Que conceito de cidadania é esse que a legislação espera que seja contemplado pelos alunos do ensino médio? Essa interpretação contida nesse documento (legislação) favorece o exercício do filosofar discente ou limita diretamente o pensamento e as possibilidades de criações conceituais dos alunos? O objetivo

\begin{tabular}{|l|l|l|l|l|}
\hline Q Ronista Dialectus & Ano 10 & n. 23 & Maio - Agosto 2021 & p. $120-137$ \\
\hline
\end{tabular}


da filosofia enquanto componente curricular do ensino médio é de fato contribuir para o exercício da cidadania ou mesmo para a sua construção?

Esses são questionamentos que devem ser levados em consideração no momento em que nos propomos a discutir o ensino de filosofia no ensino médio brasileiro. Em decorrência disso, o ensino de filosofia, apresenta-se hoje como objeto de estudo da própria filosofia tendo em vista a necessidade de se compreender a verdadeira essência de todo esse processo gradual de ensino a ser trilhado por aquele que se ensina e da real importância desse compromisso e responsabilidade assumidos diante da tarefa docente proposta no ensino de Filosofia, pois segundo Cerletti (2008, p.09).

\begin{abstract}
Ensinar implica assumir um compromisso e uma responsabilidade muito grande. Um bom docente será alguém que se situa à altura dessa responsabilidade e problematiza sempre que é o que ele ou ela realiza enquanto ensinante e, em nosso caso, que sentido há em fazê-lo, sob a denominação "fillosofia". Os melhores professores e professoras serão aqueles que possam ensinar em condições diversas, e não só porque terão que idear estratégias didáticas alternativas, mas também porque deverão ser capazes de repensar, no dia a dia, os próprios conhecimentos, sua relação com a filosofia e o marco em que pretendem ensiná-la.
\end{abstract}

Isso remete-se a possível ideia de que o professor de filosofia deve ir além da transmissão da matéria; ele deve ser uma presença que estimule a reflexão crítica sobre os saberes, de modo que sua prática consista em ajudar o aluno a aprender a filosofar, estimulandoo a exercitar a filosofia enquanto prática de vida ativa e não como mera contemplação, fazendo com que os alunos passem a levar uma vida pautada na criação enquanto ação. Vale ressaltar aqui que na perspectiva deleuziana o professor é também visto como um filósofo e como tal deve tentar fugir da tentação de pensar a filosofia como mera representação do mundo buscando assim ministra-la como criação de forma que leve os estudantes a também pensa-la como criação.

Por essa razão, Gilles Deleuze, filósofo francês, vinculado aos denominados movimentos pós-estruturalistas, defende a necessidade da problematização filosófica enquanto uma possível estratégia de ensino capaz de ressignificar o ensino de filosofia do ensino médio dando-lhe uma roupagem mais abrangente, contextualizada e verdadeiramente filosófica, possibilitando ainda o exercício do pensamento por parte dos professores de filosofia diante da preocupação sobre o que fazer e como fazer com o ensino de filosofia.

\title{
Um olhar na história do Ensino de Filosofia no Brasil
}

\begin{tabular}{|l|l|l|l|l|}
\hline Rovista Dialectus & Ano 10 & n. 23 & Maio - Agosto 2021 & p. 120 - 137 \\
\hline
\end{tabular}


Ao analisarmos a trajetória histórica do Ensino de Filosofia no Brasil, é possível percebermos a predominância de inúmeros problemas que estão interligados com a legitimação e garantia dessa disciplina no currículo educacional médio. Diante disso, constata-se que para pensar o exercício da Filosofia no Ensino Médio Brasileiro faz-se necessário conhecer a contextualização desses problemas.

Dentro desse contexto, podemos dizer ainda que apesar das constantes mudanças ocorridas ao longo do tempo, muitos desses empecilhos anteriormente citados, ainda predominam até os dias atuais, refletindo assim de maneira negativa na filosofia enquanto disciplina principalmente no que se refere ao ensino desta no cenário educacional. Por esta e outras razões se faz necessário fazer este passeio pela história da filosofia no Brasil, analisando filosoficamente a contextualização do problema e o papel exercido por esta área de conhecimento em diferentes contextos educacionais.

Estudos revelam que desde o período do Brasil Colônia, Portugal já detinha uma forte influencia sobre as ideias dos indivíduos que aqui habitavam. Naquele tempo, a filosofia no Brasil era sinônimo de luxúria e elevação de status da população dominante. Como enfatiza Cartolano (1985, p .20): “A filosofia foi no Brasil, desde os tempos coloniais, um luxo de alguns senhores ricos e ilustrados: do colono branco que aqui chegara e que constituíra a classe dominante da colônia, conservando os hábitos aristocráticos da classe dirigente da metrópole”. No entanto, diante dos inúmeros acontecimentos históricos ocorridos naquele tempo, especificamente as crises políticas e financeiras, a filosofia foi se expandindo e disseminando nos intelectuais uma necessidade e desejo por conquistar uma autonomia política frente ao cenário em que estavam expostos. Como bem mostra os livros que retratam a história da Filosofia.

Naquele período a influencia religiosa era muito forte, por essa razão, a filosofia que chegou ao Brasil acabou assumindo um caráter meramente enciclopédico e religioso, tendo em vista que os professores de Filosofia aqui existentes eram oriundos de escolas com ensinamentos jesuíticos e adeptos de uma metodologia de ensino literalmente escolástica e enciclopédica. Como afirma Costa (1967, p. 08): “A filosofia era assim considerada uma disciplina livresca. Da Europa ela nos vinha já feita. Era sinal de grande cultura o simples fato de saber reproduzir as ideias mais recentemente chegadas. A novidade supria o espírito de análise, a curiosidade supria a crítica". Fomentando ainda mais essa discussão, Franca, (1952.p.93) destaca que:

\begin{tabular}{|l|l|l|l|l|}
\hline Q & Ano 10 & n. 23 & Maio - Agosto 2021 & p. $120-137$ \\
\hline
\end{tabular}


Uma característica que se apresentou bastante saliente nessa época foi a de que a Filosofia não era trabalhada de forma reflexiva. Sua instrução estava voltada para que nenhuma pessoa introduzisse novos questionamentos a respeito de sua matéria, sem antes consultar os superiores.

Portanto, percebe-se que essa primeira fase do ensino da Filosofia no Brasil foi fortemente marcada pela influência dos jesuítas que priorizavam a catequese como objetivo educacional. No entanto, esse teocratismo desenvolvido pelos jesuítas provocou uma espécie de monopólio de pensamento que direto ou indiretamente acabou afastando Portugal das colaborações científicas daquele período.Esse afastamento de Portugal acabou por desencadear um clima de entusiasmo induzindo muitos intelectuais brasileiros a se espelharem nas ideias filosóficas da Europa. Dessa forma, os cursos de Filosofia passavam a aderir conteúdos pautados por um espírito humanista e universalista.

Com o passar dos anos a filosofia passou obrigatoriamente a fazer parte das matrizes curriculares dos cursos secundários. Com as diversas transformações políticas, econômicas, social e cultural a filosofia ganhou ainda mais força e por volta da segunda metade do século XIX "novas ideias começaram a participar da vida intelectual brasileira e a determinar um progresso do espírito crítico" (CARTOLANO, 1985, p.30), respingando fortemente no contexto da Educação filosófica, tendo em vista que a filosofia estimulava o pensamento crítico e transformador da sociedade passando assim a ser visto como uma espécie de ameaça racional à ordem vigente, frente aos reais problemas e interesses sociais da época.

Entretanto, "houve a promulgação da primeira Lei de Diretrizes e Bases da Educação, por volta do ano de 1961 (Lei 4.024/61), e a disciplina de Filosofia deixou de ser obrigatória, tornando-se um componente curricular meramente complementar" Gallina, (2000, p.17). E mais uma vez o ensino de Filosofia enquanto componente curricular foi diretamente afetado, prejudicando assim a tentativa de inserção da filosofia nas matrizes curriculares das instituições escolares brasileiras.

Nessa mesma época ocorreu o Golpe Militar e o Brasil passa a ser governado pelo exército que adotou um regime ditatorial, atingindo assim todos os segmentos nacionais, inclusive o campo educacional. Diante desse contexto, Cartolano, (1985. p.74), ressalta que "procurou-se aniquilar essa atividade reflexiva, substituindo-a por outra de caráter mais catequista e ideológico, a nível político”. Em outras palavras, pode-se dizer que houve uma substituição da atividade verdadeiramente filosófica por uma educação moral e cívica voltada para as necessidades da época.

\begin{tabular}{|l|l|l|l|l|}
\hline Q Povista Dialectus & Ano 10 & n. 23 & Maio - Agosto 2021 & p. $120-137$ \\
\hline
\end{tabular}


Com o passar do tempo começaram a chegar ao Brasil empresas multinacionais e com isso houve uma reorganização do ensino de $1^{\circ}$ e $2^{\circ}$ grau, pela Lei de Diretrizes e BasesLDB n ${ }^{\circ} 5692 / 71$, trazendo uma proposta de uma Educação Profissionalizante que atendesse de maneira mais eficaz as necessidades educacionais daquele período. Segundo Aranha,

Com a chegada das empresas multinacionais, passou a se necessitar de mão de obra técnica. Desta forma, a tendência que começava a se desenvolver no país era a de aplicar na escola o modelo empresarial, buscando adequar a educação às exigências da sociedade industrial e tecnológica, com economia de tempo e custos (ARANHA, 2001.p. 57).

Com esta reorganização, a filosofia foi completamente descartada do currículo básico de $1^{\circ}$ e $2^{\circ}$ grau do ensino secundário, pois de acordo com o governo não haveria espaço para a filosofia frente à nova demanda educacional da época. Tudo isso, gerou um sentimento de revolta em alguns educadores e filósofos desencadeando assim inúmeras mobilizações em prol do retorno da filosofia enquanto disciplina do ensino secundário, o que resultou no Art. 36 da Lei $n^{\circ}$ 9394/96 que estabelecia que ao final do ensino médio, os discentes precisavam desenvolver habilidades e conhecimentos que contemplassem os saberes de filosofia indispensáveis ao exercício pleno da cidadania.

Por meio do Projeto de Lei $\mathrm{n}^{\circ} 3.178 / 97$ aprovado no ano de 2001 que "visava modificar a terceira e atual Lei de Diretrizes e Bases da Educação Nacional, a LDB n ${ }^{\circ}$ 9.394/96" (BRASIL,1996), os estados brasileiros foram obrigados a fazerem a adesão da disciplina de Filosofia em seus respectivos currículos dos três anos do ensino médio.

Essa breve retrospectiva nos permite compreender que o ensino de filosofia na escola secundária brasileira já existe desde o período do Brasil colônia e desde esse tempo já se nota a enorme dificuldade da consolidação da filosofia enquanto componente curricular. Devido às diferentes orientações que foram ao longo do tempo sendo conferidas a esse nível de ensino, os diferentes sentidos e as mais diversas finalidades da filosofia enquanto disciplina, também acabaram sofrendo muitas oscilações. Por essa e outras razões, nos últimos tempos o ensino de filosofia no ensino médio tem se tornado alvo de muitas discussões fazendo com que os filósofos ou professores de filosofia precisem está constantemente defendendo ou justificando a utilidade da filosofia e a importância desta dentro do currículo escolar.

No livro Filosofia do Ensino de Filosofia (2003) - Vol. VII o autor Walter Omar Kohan (2003, p. 33) afirma que:

\begin{tabular}{|l|l|l|l|l|}
\hline Q Povista Qialectus & Ano 10 & n. 23 & Maio - Agosto 2021 & p. $120-137$ \\
\hline
\end{tabular}




\begin{abstract}
"Para que filosofia?" é uma dessas perguntas com história abundante e futuro assegurado. É, além disso, uma pergunta que muitos filósofos, e só eles gostam de fazer. No fundo, parece tratar-se não só de uma questão de gosto, mas de inevitável busca de legitimação teórica de uma disciplina que, só por seu nome não goza como outras desse privilegio. Tem-se que justificar os para que da filosofia, porque sua utilidade e seu sentido não costumam estar outorgados previamente.
\end{abstract}

Tomando por base essa concepção, compreendemos que dentro do próprio contexto educacional e filosófico, a filosofia enfrenta uma espécie de discriminação frente às demais disciplinas que compõem o currículo médio. E é por isso que existe uma preocupação por parte de quem é da respectiva área, em tentar legitimar a sua real importância para àqueles que a desconhecem verdadeiramente. Embora saibamos que como afirma Georges Canguilhem (1975): “a filosofia não tem necessidade de defensores, na medida em que sua justificação é assunto seu. Mas a defesa do ensino da filosofia terá necessidade de uma filosofia critica do ensino".

Isso significa dizer que a importância da filosofia e seu ensino precisam ser discutidos a partir da própria filosofia, tendo em vista que o ensino filosófico e a justificação do mesmo, é algo de interesse não mais apenas dos filósofos, mas dos educadores de modo geral, por tratar-se de uma área do conhecimento que está completamente interligada com as demais que compõem o currículo básico. Nesse contexto, podemos referenciar Montaigne, (1994, cap.26) ao afirmar que:

A filosofia deve ser uma matéria na educação dos pequenos, para formar pessoas mais inteligentes, felizes e ajuizadas, mais livres de espírito. Se não se quer tornar as crianças seres servis e tímidos, deve-se dar-lhes a oportunidade de fazer algo por si mesmas, pois o ensino de filosofia é a peça chave de uma formação humanista para a autonomia.

Frente a todo esse processo histórico percorrido pela filosofia na tentativa de se auto firmar como disciplina curricular obrigatória indispensável na formação do individuo, compreende-se uma necessidade de se propagar de maneira positiva as ideias propostas por Montaigne (1994) e tantos outros teóricos que defendem a filosofia e seu respectivo ensino. No entanto, não estamos falando de qualquer tipo de ensino filosófico, mas de um ensino que fuja do modelo jesuítico e que seja condizente com o atual contexto vivenciado hoje por alunos e professores no âmbito do Ensino Médio.

Em relação a esse ensino, podemos perceber que a cada dia que passa tem sido mais recorrente o índice de estudos que têm sido desenvolvidos em torno dessa temática. Estes por

\begin{tabular}{|l|l|l|l|l|}
\hline Rovista Dialectus & Ano 10 & n. 23 & Maio - Agosto 2021 & p. $120-137$ \\
\hline
\end{tabular}


sua vez, ganharam uma maior densidade e foram se fortalecendo ao longo do tempo, a medida em que apresentavam interesses em discutir concepções e possibilidades que favorecessem a aplicação do ensino de filosofia de forma ativa e que viesse de encontro à realidade dos alunos de ensino médio.

Frente a isso, é válido ressaltar que a relevância desses estudos não se deve à proposições de estratégias ou livros de receitas de como ensinar filosofia, mas as diversas tentativas de fazer com que os professores, através desses estudos sejam capazes de pensar sobre o ensino da respectiva área de conhecimento e consequentemente sobre as práticas metodológicas que tem sido desenvolvidas pelos mesmos em sala de aula, buscando assim aperfeiçoar suas práticas docentes.

É importante lembrar que esse processo não está diretamente interligado a ideia de seguir caminhos pré-estabelecidos e dispostos nesses estudos, ou seja, o fazer como, mas tratase de uma resignificação didática a partir de abordagens apresentadas, que por sua vez não devem ser encaradas como manual de instruções e sim como pistas que procuram responder como se ensinar filosofia de maneira mais prática e eficaz. A noção dessa importância será mais bem assimilada, quando compreendermos o real contexto da filosofia no ensino médio atual e as múltiplas compreensões existentes hoje em torno do seu ensino.

\section{O Ensino de Filosofia na contemporaneidade e suas múltiplas compreensões}

Analisando todo o percurso histórico da filosofia, especificamente as lutas pela permanência da mesma nos currículos do ensino médio percebe-se que muitas foram as dificuldades enfrentadas e maiores ainda são os obstáculos existentes em torno do seu ensino e que precisam ser superados. Isso acontece, porque a filosofia instaurada pelos documentos oficiais no ensino médio atual é uma filosofia que deve cumprir determinadas intenções ou interesses que favoreçam uma necessidade ideológica exigida pelo sistema educacional e muito bem exposto na LDB (Lei de Diretrizes e Bases) n 93.9496 bem como nos Parâmetros Curriculares Nacionais- PCN's.

No entanto, toda essa intencionalidade filosófica proposta pelos respectivos referenciais, foge à real função e intenção da filosofia. Na obra Metodologia do Ensino de Filosofia, Silvio Gallo (2012) (caracteriza a filosofia do ensino médio atual como "uma filosofia deslocada da vida e do cotidiano. Uma filosofia voltada para a erudição ou então para o exercício da cidadania plena, por exemplo".

\begin{tabular}{|l|l|l|l|l|}
\hline Q & Ano 10 & n. 23 & Maio - Agosto 2021 & p. $120-137$ \\
\hline
\end{tabular}


Em uma era onde as pessoas precisam ser cada vez mais motivadas a praticarem o exercício do pensamento, é preciso repensar essa proposta de ensino médio existentes hoje dentro das escolas. Para isso, faz-se necessário que deixemos de lado as cartilhas que envolvem meramente conteúdos históricos e tentemos priorizar aulas de filosofia que discutam assuntos inerentes à realidade discente de forma a contribuir reflexivamente para as vivencias diárias dos jovens. Tentando sempre enxergar o ensino de filosofia sob uma ótica que transcenda a sua intencionalidade ética e de formação cidadã.

Em outras palavras, pode-se dizer que pensar o exercício da filosofia na escola média da atualidade requer esforço e adesão à diversidade, objetivando encarar com uma maior seriedade as controvérsias existente desse processo. Para isso, faz-se necessário que busquemos refletir filosoficamente sobre o real conceito da filosofia ensinada dentro das instituições escolares nesses tempos hipermodernos, qual a sua verdadeira função enquanto componente curricular da educação básica, na maneira como esta disciplina tem sido ensinada pelos professores em sala de aula e nos efeitos que estas práticas educativas veem surtindo na vida e no cotidiano dos discentes de ensino médio.

Buscando responder aos questionamentos dispostos no parágrafo anterior, precisamos romper ou no mínimo contrariar as intencionalidades pedagógicas propostas pela legislação no que tange à disciplina de filosofia na escola média. E para fortalecer teoricamente o discurso aqui apresentado, sirvo-me mais uma vez dos pensamentos de Sílvio Gallo (2012) quando este afirma:

\footnotetext{
Penso que a filosofia pode, de fato, contribuir para o exercício da cidadania e mesmo para a sua construção, ela não pode e nem deve ser limitada a isso. A sua justificação deve se dar pelo papel que apenas ela pode desempenhar no processo de formação dos jovens. É a partir da clareza sobre esse papel que poderemos delinear as possibilidades e os limites da filosofia na vida dos jovens. E apenas depois de alguns anos em que a experiência do ensino de filosofia esteja generalizada e consolidada, é que poderemos tentar entender suas contribuições. (GALLO, 2003, p.37).
}

Com base no exposto, somos levados a refletir sobre o conceito errôneo existente hoje nas escolas de ensino médio acerca da disciplina de filosofia. Tal conceito foi institucionalizado e culturalmente internalizado pelos professores. A limitação da filosofia como uma disciplina comum que por meio de metodologias prontas exige dos alunos, apenas a aquisição de competências e habilidades que contemplem os direitos de cidadania.

\begin{tabular}{|l|l|l|l|l|}
\hline Q Povista Q Dialectus & Ano 10 & n. 23 & Maio - Agosto 2021 & p. $120-137$ \\
\hline
\end{tabular}


A ideia aqui apresentada não é desmentir a teoria de que a filosofia favorece a formação cidadã do aluno, mas criticar essa limitação da disciplina, pois compreendemos que isso singulariza a filosofia e contradiz completamente a ideia de pluralidade, multiplicidade, proposta por Gilles Deleuze, quando o mesmo defende a filosofia como criadora de conceitos, ou seja, como uma disciplina que tem suas próprias especificidades e que não pode jamais ser limitada a uma didática que obedece rigorosamente a um viés positivista já pré-estabelecido.

\section{O Ensino de Filosofia e a pedagogia do conceito de Gilles Deleuze e Félix Guattari}

A filosofia sob a ótica conceitual de Gilles Deleuze e Félix Guattari é uma das preocupações centrais abordadas na obra $O$ que é filosofia? publicada em 1991 na França pelos respectivos autores. O pensamento desenvolvido pelos teóricos na respectiva obra traz a tona um novo entendimento sob a concepção da filosofia. Para eles a filosofia, caracteriza menos a busca da verdade e muito mais a possibilidade de que se inaugure, no seu interior, uma nova imagem de pensamento. De acordo com suas concepções, a filosofia pode ser apontada como "a arte de criar conceitos", opondo-se a filosofia clássica - como uma filosofia que pensa a partir de pressupostos e postulados.

Esses pressupostos e postulados que se apresentam como peculiaridades da filosofia nos mostra que a filosofia por si só possui uma especificidade própria que de acordo com Gallo (2012.p.54), podemos tomar como sendo três as principais características da filosofia:

1- Trata-se de um pensamento conceitual: enquanto saber, ela é sempre produto de pensamento, é uma experiência de pensamento. Mas o que caracteriza a filosofia é que ela é uma experiência de pensamento que procede por conceitos, que cria conceitos, à diferença da ciência e da arte;

2- $\quad$ Apresenta um caráter dialógico: ela não se caracteriza como um saber fechado em si mesmo, uma verdade dogmática, mas como um saber que se experimenta, que se confronta consigo mesmo e com os outros, que se abre ao diálogo com outros saberes, um saber aberto e em construção coletiva;

3- Possibilita uma postura de critica radical:a atitude filosófica é a da não conformação, do questionamento constante, da busca das raízes das coisas, não se contentando com respostas prontas e sempre colocando em xeque as posturas dogmáticas e as certezas apressadas.

Embora outras disciplinas do currículo médio também sejam adeptas de características que remetem ao diálogo e a criticidade, a filosofia possui um caráter filosófico específico que a distingue completamente dos demais campos de conhecimento, sejam eles artísticos ou científicos, que é exatamente o trato com o conceito. Deleuze e Guattari pensam a filosofia como "atividade filosófica produtora de conceitos que aguça a imaginação". Para eles,

\begin{tabular}{|l|l|l|l|l|}
\hline Q Rovista Dialectus & Ano 10 & n. 23 & Maio - Agosto 2021 & p. 120 - 137 \\
\hline
\end{tabular}


a Filosofia é a própria vida ativa, e enquanto atividade contraria a ideia de contemplação imposta pelos documentos oficiais que fomentam o currículo do ensino médio da atualidade, uma vez que defende que o fazer docente do filósofo deve configurar uma ação de criação. Segundo Cerletti (2008, p.09):

\begin{abstract}
A docência em filosofia convoca os professores e as professoras como pensadores e pensadoras, mais do que como transmissores acríticos de um saber que supostamente dominam ou como técnicos que aplicam estratégias didáticas ideadas por especialistas para ser empregadas por qualquer um, em qualquer circunstancia.
\end{abstract}

No âmbito dessas reflexões, pensamos que desenvolver educação filosófica que não discuta, problematize e questione o ambiente familiar, social, educacional e profissional do aluno é pensar em um ensino de filosofia duvidoso e incompleto. Por essa razão, aposta-se na possibilidade do ensino de Filosofia sob a ótica Deleuziana, tendo em vista que os adeptos dessa corrente defendem que o ensino de filosofia deve ser capaz de propiciar ao alunado o gosto pelo pensamento, cativando encontros intensivos capazes de potencializar o gesto criativo que definiria a atividade filosófica, a criação conceitual e assim possibilitar o surgimento de uma enigmática figura: o filósofo.

Os diversos entraves existentes hoje no ensino de filosofia do ensino médio brasileiro devem-se à ausência do uso da filosofia no momento em que seu ensino enquanto componente curricular é pensado. Gallo (2012. p. 53) defende que:

\footnotetext{
Uma didática geral, uma arte de ensinar tudo a todos não pode dar conta do ensinar filosofia, do aprender filosofia. Filosoficamente, o aprendizado da filosofia está para além de qualquer método, que significa controle. No processo de ensino a filosofia nos escapa... E, no entanto, penso que devemos nos dedicar a essa aventura que é o ensino de filosofia. Sim, aventura, pois sabemos quando e de onde saímos, mas não sabemos quando, aonde ou mesmo se chegaremos. O ensino de Filosofia não pode ser abarcado por uma didática geral, não pode ser equacionada unicamente como uma questão pedagógica, porque há algo de específico na filosofia. Há algo que faz com que a filosofia seja Filosofia - e não ciência, religião, ou opinião-, e é esse algo que faz com que o ensino de filosofia careça também de um tratamento filosófico, de uma didática específica para além de toda e qualquer questão estritamente pedagógica.
}

Nota-se a urgente necessidade de se pensar filosoficamente o ensino de filosofia no ensino médio atual, buscando romper com essa didática meramente histórico-filosófica com estratégias de ensino contemplativa que se instaurou como metodologia cultural que unifica pedagogicamente a filosofia enquanto conceito e criadora destes.

Deleuze e Guattari (1992, p.53) discutem que:

\begin{tabular}{|c|c|c|c|c|}
\hline Q Rovista Dialeatus & Ano 10 & n. 23 & Maio - Agosto 2021 & p. $120-137$ \\
\hline
\end{tabular}


Onde há apenas contemplação, reflexão e comunicação, não há filosofia, pois essas faculdades são máquinas de construir Universais. O fato de ter de ser criado impede ao conceito a universalidade. "Os conceitos não nos esperam inteiramente feitos. Não há céu para os conceitos“. Resta saber: que unidade resta à filosofia? Pouca ou nenhuma.

As ideias dos autores perspectivam um ensino de filosofia no ensino médio que favoreça a criação de pensamentos que fomentem a criação do novo por meio da filosofia. Como é dito na obra $O$ que é a filosofia?: "O conceito é o contorno, a configuração, a constelação de um acontecimento por vir. Os conceitos nesse sentido pertencem de pleno direito a filosofia, porque é ela que os cria e não cessa de criá-los”. (DELEUZE; GUATTARI, 1992, p. 46). Além disso, os autores ressaltam ainda que: “O conceito filosófico não se refere ao vivido, por compensação, mas permite por sua própria criação, em erigir um acontecimento que sobrevoe todo o vivido, bem como qualquer outro estado de coisas. Cada conceito corta o acontecimento, o recorta a sua maneira”. “(1992.p. 47).

Frente a isso, sugere-se que o professor apresente os principais problemas filosóficos desenvolvendo a problematização e a compreensão da atualidade pelos educandos. Pensados os problemas filosóficos, os alunos são levados a pensar sobre suas próprias existências e sobre os conceitos já existentes no mundo atual. O fato de o conceito brotar de problemas, de buscar equacioná-los é que faz da filosofia essa "obra aberta, uma vez que os conceitos nunca são conclusivos, mas continuam carregando em si os problemas que lhes deram origem." (GALLO, 2012, p.55). Essa persistência do problema no pensamento é bem ressaltada por Deleuze (2006a, p.267):

\footnotetext{
Um problema não existe fora de suas soluções. Mas em vez de desaparecer, ele insiste e persiste nas soluções que o recobrem. Um problema se determina ao mesmo tempo em que é resolvido; mas sua determinação não se confunde com a solução: os dois elementos diferem por natureza, e a determinação é como a gênese da solução concomitante (...). O problema é ao mesmo tempo transcendente e imanente em relação às suas soluções. Transcendente, porque consiste num sistema de ligações ideais ou de relações referenciais entre elementos genéticos. Imanente, porque estas ligações ou relações se encarnam nas correlações atuais que não se assemelham a elas e que são definidas pelo campo de solução.
}

Pensar a filosofia sob essa perspectiva da pedagogia do conceito é pensar em vencer essa tensão curricular e metodológica existente hoje em torno do processo de ensino de filosofia na escola não problematizadora. Pensar a filosofia sob a perspectiva da persistência do problema nos possibilitará enxergar o ensino sob um novo conceito.

\begin{tabular}{|c|c|c|c|c|}
\hline Gonita Q Oialectus & Ano 10 & n. 23 & Maio - Agosto 2021 & p. $120-137$ \\
\hline
\end{tabular}


O redescobrimento do ato filosófico se dá a partir da articulação do professor filósofo que na prática atua como "não filósofo" e saber articular seus conhecimentos em sala de aula ou na escola, de modo geral, para juntamente com seus discentes redescobrir algo novo: o filosofar. Deleuze e Guattari (1992, p.143) confirmam essa ideia quando afirmam que "O filósofo deve tornar-se não filósofo, para que a não filosofia se torne a terra e o povo da filosofia.[...]Tornar-se estrangeiro a si mesmo, e à sua própria língua e nação, não é o próprio do filósofo e da filosofia, seu estilo, o que se chama um galimatias filosófico?"

Em outras palavras, podemos dizer que de acordo com a concepção deleuziana não se pode criar metodologias ou oficinas para ensinar filosofia, tendo em vista a teoria da multiplicidade, do devir, do acontecimento tão bem defendidas por Deleuze. O que é possível é criar possibilidades de se trabalhar, essas possibilidades devem ser criadas por cada professor como construção da sua individualização. Dentro desse contexto vale-se destacar que para que haja essas possibilidades o professor precisa ir além do rompimento com a sua velha estratégia de ensinar enciclopedicamente, é preciso que este venha a desnudar-se de alguns velhos paradigmas adotando a postura de um mestre que sabe, mas que apesar de saber coloca-se também na condição de aprendiz e aventura-se mentalmente com seus alunos em busca do novo, de modo que os educandos desenvolvam também a capacidade de pensar a sua realidade, refletir sobre os problemas e saberes da contemporaneidade a partir de uma ótica filosófica para que o ato filosófico se dê. Sobre isso Gallo (2012, pág. 43) afirma que:

[...] O filósofo francês Michel Foucault, por exemplo, caracterizou a atividade filosófica como uma espécie de 'exercício de si, no pensamento'. Isto é, como um trabalho de pensar sobre si mesmo que faz com que cresçamos e nos modifiquemos como pessoas. Sendo o ensino médio uma fase de consolidação do jovem, de sua personalidade, de seus anseios, a filosofia tem ai um importante papel e uma colaboração.

Em defesa de um ensino dialógico, que visa à construção da autonomia e da identidade filosófica- sendo esta interpretada "no sentido da formação de indivíduos que possam escolher por si mesmos em que mundo querem viver" (GALLO \& KOHAN, 2000, p. 195) -, acreditamos que o ensino de Filosofia não pode basear-se somente nos conteúdos. O professor deve ir além da transmissão da matéria; atuando como uma presença que estimule a reflexão crítica sobre os saberes, de modo que sua prática consista em ajudar o aluno a aprender a filosofar. "Sob pena de criar mentes servis, dependentes e tuteladas não devemos ensinar pensamentos, mas podemos ativar o exercício do pensar” (RAMOS, 2007, pp. 201-2).

\begin{tabular}{|c|c|c|c|c|}
\hline Q Rovista Dialeatus & Ano 10 & n. 23 & Maio - Agosto 2021 & p. $120-137$ \\
\hline
\end{tabular}


Pensar é experimentar, mas a experimentação é sempre o que se está fazendo - o novo, o notável, o interessante, que substituem a aparência de verdade e que são mais exigentes que ela. [...] A história não é experimentação, ela é somente o conjunto das condições quase negativas que tornam possível a experimentação de algo que escapa à história. Sem história, a experimentação permaneceria indeterminada, incondicionada, mas a experimentação não é histórica, ela é filosófica" (DELEUZE, 1992, p.133).

Para que seja possível ensinar filosofia no ensino médio na perspectiva deleuziana é preciso que as aulas propostas pelos professores priorizem a formação de conceitos, pois sem esta, os alunos tendem a produzir reflexões que não saem do senso comum. As aulas limitamse ao "achismo", os alunos apenas expressam suas opiniões sem levar em conta os pensamentos filosóficos. Desta forma o conhecimento é feito a partir de uma metodologia transmissora e o ensino encerra-se em si mesmo sem proporcionar a criação de algo novo. E segundo Sílvio Gallo (2010, p. 90), esse não é o real objetivo da Filosofia no Ensino Médio, pois segundo ele:

O que realmente justifica a presença da filosofia como disciplina no currículo do ensino médio é a oportunidade que ela oferece aos jovens estudantes de desenvolverem um pensamento critico e autônomo. Em outras palavras, a filosofia permite que eles experimentem um "pensar por si mesmos".

Neste sentido, o exercício do pensamento sobre os conhecimentos filosóficos podem nos possibilitar a compreensão dos demais tipos de conhecimento, atribuindo a estes, sentidos significativos em nossas vidas (SEVERINO, 2003). Em defesa dessa nova proposta Gallo (2012, p. 70) reforça ainda a perspectiva de Deleuze e Guattari afirmando que "[...] Não se produz filosofia sem um problema, o que nos leva a afirmar que o problema é o motor da experiência filosófica do pensamento". Compreendemos assim que todo professor de filosofia deve ter clara sua concepção de filosofia e uma delas, entre outras, é a perspectiva Deleuziana que traz em suas bases a possibilidade da construção/criação de conceitos, desvinculando o ensino da mera contemplação pedagógica de conhecimentos livrescos.

\section{Considerações finais}

Ao discutir acerca do ensino de filosofia no ensino médio e a pedagogia do conceito compreendemos ser esta uma reflexão necessária para a qualificação do ensino, uma vez que se torna evidente que a produção do conhecimento filosófico requer problematização e a própria criação de conceitos. Desta maneira, defende-se a ideia de que é necessário que o ensino de

\begin{tabular}{|c|c|c|c|c|}
\hline Qovista Dialectus & Ano 10 & n. 23 & Maio - Agosto 2021 & p. 120 - 137 \\
\hline
\end{tabular}


filosofia no Ensino Médio ganhe uma nova roupagem e passe a ser ministrado e mediado por meio de aulas que valorizem e ampliem gradativamente o discurso e a criação conceitual do aluno dentro e fora da escola por meio de ações interdisciplinares na possível expectativa de formar sujeitos autônomos, críticos e responsáveis capazes de compreender filosoficamente e transformar a realidade em que vivem a partir de novos conceitos, conforme afirma Deleuze.

Acredita-se que colocando em prática metodologias de ensino de filosofia que associam os conteúdos do ensino médio com os saberes filosóficos dentro de uma perspectiva ontológica, defendidos por Deleuze, Guattari, Gallo, Cerlleti e tantos outros filósofos anteriormente citados,contribuiremos com a resignificação do ensino de Filosofia no Ensino Médio, rompendo com os paradigmas da filosofia tradicional e motivando o exercício do pensamento em busca de um ensino ativo, criativo e criador, favorecendo assim a construção de novos conceitos.

\section{Referências}

ARANHA, Maria Lúcia de Arruda. História da Educação. $2^{\circ}$ edição. São Paulo: Moderna, 2001.

BRASIL. Lei Ordinária 11.684 de 02 de junho de 2008. Altera o art. 36 da Lei 9394, de 20 de dezembro de 1996, que estabelece as diretrizes e bases da educação nacional, para incluir a Filosofia e a Sociologia como disciplinas obrigatórias nos currículos do ensino médio. Diário Oficial da União, Brasília, DF, 03 de junho de 2008.

BRASIL. Ministério da Educação. Lei de Diretrizes e Bases da Educação Nacional (LDB). Lei n ${ }^{\circ}$ 9.394/96. Brasília:MEC, 20 dez. 1996.

BRASIL. Lei $\mathrm{n}^{\circ}$ 4.024, de 20 de dezembro de 1961. Fixa as diretrizes e bases da educação nacional. Lei de Diretrizes e Bases da Educação-LDB. Brasília, DF, 1961. Disponível em: Acesso em 14 de junho de. 2020.

BRASIL, Ministério da Educação. Secretaria de Educação Média e Tecnológica. Conhecimentos de filosofia. In: Parâmetros Curriculares Nacionais: ensino médio. Brasília: MEC/SEMT, Cento Gráfico, 1999.

CARTOLANO, Maria Teresa Penteado. Filosofia no ensino de $2^{\circ}$ grau. São Paulo: Cortez: Autores Associados, 1985.

\begin{tabular}{|l|l|l|l|l|}
\hline Q & Ano 10 & n. 23 & Maio - Agosto 2021 & p. $120-137$ \\
\hline
\end{tabular}


CERLETTI, A. O ensino de filosofia como problema filosófico. Tradução de Ingrid Muller Xavier. Belo Horizonte: Autêntica Editora, 2009.

COSTA, Cruz. 1967. Panorama da história da filosofia no Brasil. São Paulo: Cultrix.

DELLEUZE, Gilles, 1925- O que é filosofia? Tradução de Bento Prado Jr. e Alberto Afonso Muñoz. - Rio de Janeiro: ED. 34, 1992.

FRANCA, Leonel. O método pedagógico dos jesuítas. Rio de Janeiro: Agir, 1952.

FREIRE, Paulo. Pedagogia da autonomia: saberes necessários à prática educativa. São Paulo: Paz e Terra, 1996.

GALLINA, Simone F. S. A disciplina de filosofia e o ensino médio. In: GALLO, S.; KOHAN, W. O. (Orgs.). Filosofia no ensino médio. Petrópolis: Vozes, 2000.

GALLO, Silvio. Metodologia do ensino de filosofia: uma didática para o ensino médio. Campinas: Papirus, 2012.

GALLO, Silvio; KOHAN, Walter O. Crítica de alguns lugares-comuns ao se pensar a filosofia no ensino médio. In. GALLO, Silvio; KOHAN, Walter O. (organizadores). Filosofia no ensino médio. Petrópolis: Vozes, 2000.

KOHAN, Walter O. (Org.). Filosofia: caminhos para seu ensino. Rio de Janeiro: DP\&A, 2003.

RAMOS, C. A. Aprender a filosofar ou aprender a filosofia: Kant ou Hegel? Trans/Form/Ação. São Paulo, 2007. 